\title{
An investigation of bedside laparoscopy in the ICU for cases of non-occlusive mesenteric ischemia
}

\author{
G. Cocorullo ${ }^{1}$, A. Mirabella ${ }^{2}$, N. Falco ${ }^{1 *} \mathbb{D}$, T. Fontana ${ }^{1}$, R. Tutino ${ }^{1}$, L. Licari ${ }^{1}$, G. Salamone ${ }^{1}$, G. Scerrino ${ }^{1}$ and G. Gulotta ${ }^{1}$
}

\begin{abstract}
Background: Acute mesenteric ischemia is a rare affection with high related mortality. NOMl presents the most important diagnostic problems and is related with the higher risk of white laparotomy. This study wants to give a contribution for the validation of laparoscopic approach in case of NOMl.

Methods: Thirty-two consecutive patients were admitted in last 10 years in ICU of Paolo Giaccone University Hospital of Palermo for AMI. Diagnosis was obtained by multislice CT and selective angiography was done if clinical conditions were permissive. If necrosis was already present or suspected, surgical approach was done. Endovascular or surgical embolectomy was performed when necessary. Twenty NOMI patients underwent medical treatment performing laparoscopy $24 \mathrm{~h}$ later to verify the evolution of AMI. A three-port technique was used. In all patients we performed a bed side procedure 48-72 $\mathrm{h}$ later in both non-resected and resected group.

Results: In 14 up 20 case of NOMI the disease was extended throughout the splanchnic district, in 6 patients it involved the ileum and the colon; after a first look, only 6 patients underwent resection. One patient died $35 \mathrm{~h}$ after diagnosis of NOMl. The second look, $48 \mathrm{~h}$ later, demonstrated 4 infarction recurrences in the group of resected patients and onset signs of necrosis in 5 patients of non-resected group. A total of 15 resections were performed on 11 patients. Mortality rate was 6/20-30\% but it was much higher in resected group (5/11-45,5\%). Nontherapeutic laparotomy was avoided in $9 / 20$ patients and in this group mortality rate was $1 / 9-11 \%$. No morbidity was recorded related to laparoscopic procedure.

Conclusions: Laparoscopy could be a feasible and safety surgical approach for management of patient with NOMl. Our retrospective study demonstrates that laparoscopy don't increase morbidity, reduce mortality avoiding nontherapeutic laparotomy.
\end{abstract}

Keywords: Acute mesenteric ischemia, NOMI, Laparoscopy, Surgery, Intensive care

\section{Background}

Acute mesenteric ischemia is a rare affection with high related mortality. It accounts 1:1000 acute hospital admissions in Europe and the USA [1] and presents a very high mortality with a range from 50 to $69 \%[2-5]$ of cases.

The affection consists in an acute arterial occlusion due to embolism (EAMI), or thrombosis (TAMI), in a venous thrombosis (VAMI) or, at last, in an nonocclusive mesenteric ischemia (NOMI).

\footnotetext{
* Correspondence: nicola.falc087@libero.it

${ }^{1}$ General and Emergency Surgery-Policlinico P. Giaccone, University of

Palermo, Via Liborio Giuffrè, 5, Palermo, Italy

Full list of author information is available at the end of the article
}

Pathophysiology is different in each type as risk factors. Different are also comorbidities and clinical findings. In all cases diagnosis is very difficult because there aren't specific laboratory tests.

EAMI is often related to hearth disease (atrial fibrillation, myocardial infarction, etc.) and causes acute symptoms as diarrhoea, vomiting, acute abdominal pain; TAMI is characterized by more indolent onset with post-prandial pain and weight loss in patients with history of atherosclerosis, hypertension, diabetes; VAMI occurs in $10 \%$ of cases in patients with hypercoagulable disorders, malignancies, hepatitis, pancreatitis, and other affections causing slow blood flow. NOMI occurs mostly 
in critically ill patients with hypovolemia, hypotension, recent treatment with beta blockers or alpha adrenergic. Usually these are patients with endotracheal tube and symptoms can start in acute or gradual way.

Nowadays the gold standard for diagnosis is CT, which offers a good accuracy in AMI detection with high values of sensitivity and specificity [6], but it is well known that these values are not similar in each etiological type.

NOMI is an exclusion diagnosis. It presents the most important diagnostic problems due to lack of specific radiological features on $\mathrm{CT}$, which usually shows a normal bowel wall and a high variability of its contrast enhancement ranging from absent or diminished to increased [7]. So, in the suspicious of NOMI an anamnesis of low arterial flow or low cardiac output (recent cardiac failure, prolonged cardio-pulmonary resuscitation, cardiac surgery, severe cardiac failure, aortic dissection and aneurism, recent aortic vascular surgery etc..), biochemical findings (>TGO/>TGP; $>$ LDL, >CPK, > Bilirubin), signs of Acute Kidney Failure (altered level of creatinine, urea and electrolytes, reduced urine output). When possible a selective angiography or an angio-CT should be performed [8] to confirm diagnosis, exclude other form of AMI and to start the medical treatment (fluid infusion, prostaglandins, etc.) (Fig. 1).

Then NOMI needs a very close follow-up to obtain an early detection of mesenteric infarction which imposes bowel resection. Early diagnosis and prompt intervention are the goals of modern treatment. It can stop the fatal progression of sepsis that is responsible of the high mortality rate [9].
Also, the treatment is different in each type of AMI [10]: resolution of embolism in open surgery (especially if bowel necrosis is present) or in endovascular way is the choice treatment in patients with EAMI or TAMI. In case of VAMI the first choice is anticoagulation and finally in patients with NOMI the first step is the infusion of fluids and vasodilators; the last mentioned are administered directly via Superior Mesenteric Artery (SMA) when possible. If bowel necrosis is present, resection is necessary at the same time [10].

Although CT consents a differential diagnosis in patients with doubtful abdominal presentation and for these reason is the first diagnostic step for these patient, there isn't any diagnostic test which can early indicate the onset of bowel necrosis. The aim of this study is to show our results of systematic use of laparoscopy in bowel infarction detection in critical ill patients.

\section{Methods}

A retrospective study was carried out on 32 consecutive patients recovered in last 10 years (1st January 2006-31st December 2015) in ICU of Paolo Giaccone University Hospital of Palermo. The patients' age, clinical symptoms, biochemistry and radiological findings were considered.

In all patients, AMI was diagnosed by multislice CT (Fig. 2); selective angiography was done if clinical conditions were permissive.

If necrosis was already present or suspected, surgical approach was done. Moreover, endovascular or surgical embolectomy was performed in cases with EAMI or TAMI whilst VAMI and NOMI patients underwent

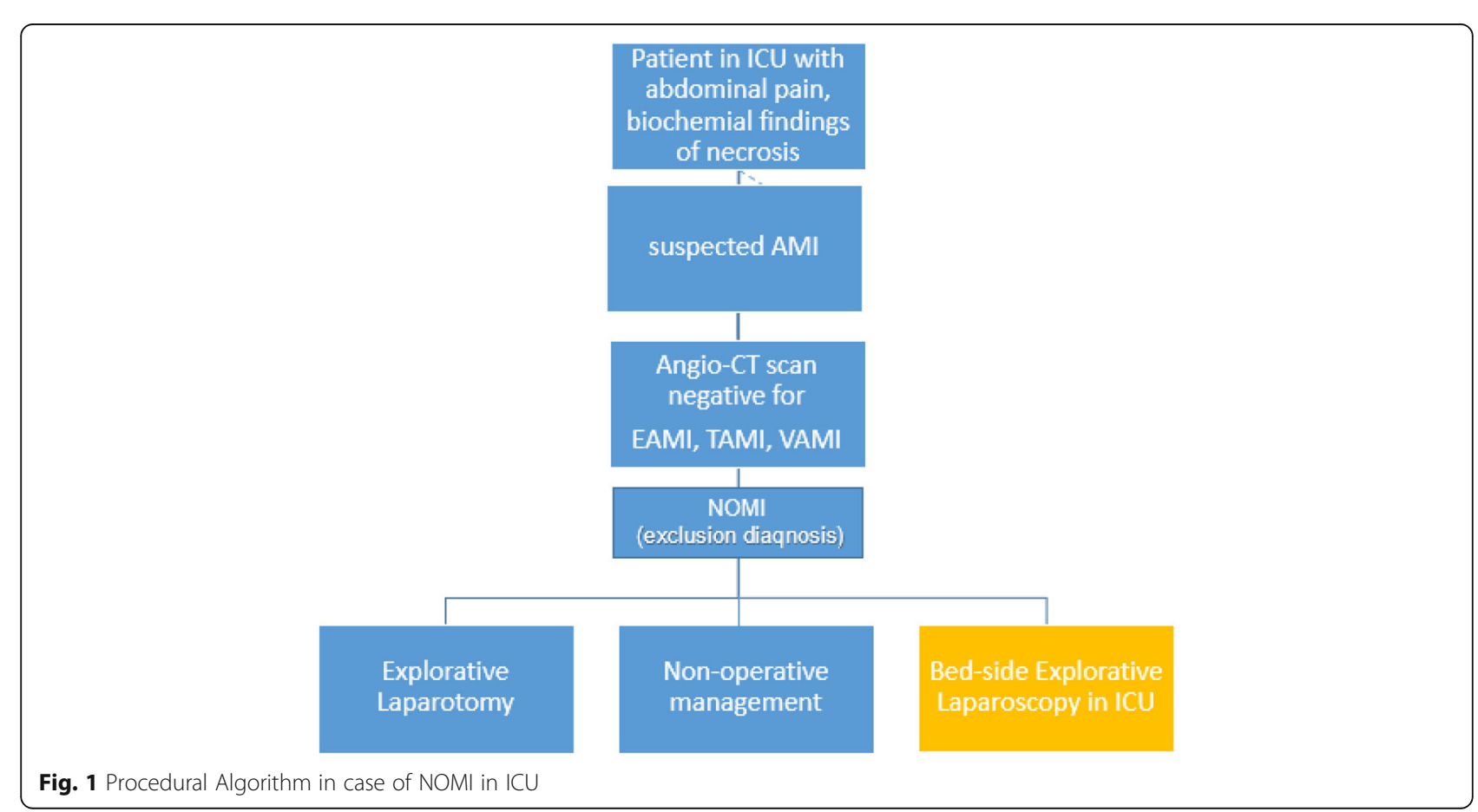




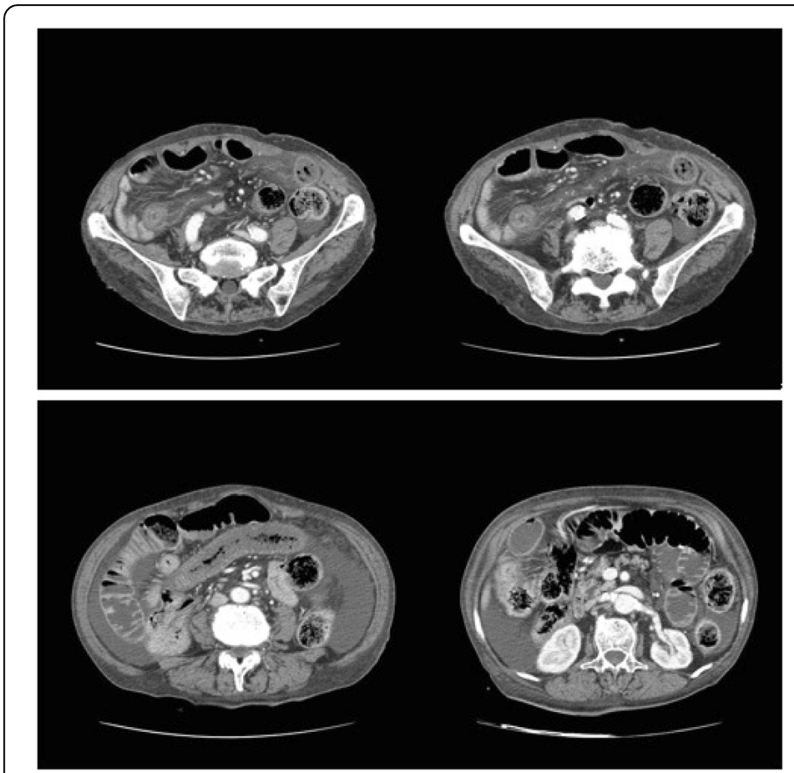

Fig 2 Angio-CT, a case of NOMl: Radiologic Science Department-AOUP Palermo

medical treatment performing laparoscopy $24 \mathrm{~h}$ later to verify the evolution of AMI.

A three-port technique was used [11, 12]: a $10-\mathrm{mm}$ camera-port was positioned through the umbilical scar. After a first exploration of the abdomen, other two $5 \mathrm{~mm}$ operative-trocars were put in the left hypochondrium and in the left iliac fossa. In this way, as in right laparoscopic colectomy, an accurate exploration of entire small bowel was possible starting from the ileocecal junction and going back up to the Treitz ligament. Colon was entirely explored. Only in 4 patients a fourth $5 \mathrm{~mm}$ port in right flank was needed.

The bowel aspect and the ischemia extension were evaluated; all patients showed widespread intestinal pallor therefore, the first suffering loop was searched (intense pallor, necrosis signs) and the necrotic bowel was resected when present. The involved bowel was mobilized and after vessels ligation it was externalized through a 5$6 \mathrm{~cm}$ laparotomy. After resection, no anastomosis was done and an ostomy was performed. The absence of signs of necrosis is not to be underestimated because of the rapid precipitation of NOMI clinical features.

Therefore, in all patient medical therapy was continued and EBPM was administered using prophylactic dosages, the procedure was repeated $48-72 \mathrm{~h}$ later (Second Look) in both non-resected and resected group, looking for new necrotic areas.

Due the organization of our Hospital in nearly but separated departments, a bed-side laparoscopy was performed to avoid the transfer of the critically ill patients to the department of radiology or to operation room that often can leads to serious difficulties especially
Table 1 Necessary equipment for bed-side laparoscopy

Laparoscopic Column including: CO2 insufflator, HD camera, light source, HD monitor

Optic $10 \mathrm{~mm}$

$N^{\circ} 2$ laparoscopic forceps

Ultrasound dissector with disposable device

$\mathrm{N}^{\circ} 3$ Trocars $(10 \mathrm{~mm}, 5 \mathrm{~mm}, 5 \mathrm{~mm})$

Surgical drapes

Basic Surgical Kit

when the transfers are multiple. A laparoscopic column and a centralized $\mathrm{CO} 2$ distribution system are available in ICU and allow the execution of bed side laparoscopy. The availability of mobilizable beds in ICU support the surgeon to perform explorative laparoscopy with low Co2 flow and pressure $(8-10 \mathrm{mmHg})$. Only two surgeons need to perform the procedure and the second or further looks are performed through the same sites used before. A 10-mm optic and two laparoscopic forceps or an ultrasound dissector allow the exploration and the dissection of bowel needs resection (Table 1). In case of re-resection the bowel was extracted trough the same previous incision and after a distal ligation of vessels, resection was performed with linear stapler. Moreover, in all cases ostomy and mucous fistula was is performed.

Safety and efficacy of the procedure was evaluated in terms of mortality, diagnosed infarctions and avoided non-therapeutic laparotomy. Postoperative morbidity was an outcome not reliable due to multiple comorbidity already present in our patients.

\section{Results}

Among 32 critical ill patients with CT report of AMI, 6 presented EAMI, 3 TAMI, 1 VAMI and 20 NOMI (Table 2).

Main biochemical and CT findings of NOMI patients are collected in Table 3. In all NOMI cases (20) an intense pallor of bowel wall was the main laparoscopic finding. In 14 cases, it was extended throughout the splanchnic district, whilst in 6 patients it involved mainly the ileum and the colon (right colon 2 cases; left colon 3 cases; entire colon 1 case); every patient in last group underwent resection to prevent bowel necrosis and peritonitis in 5 cases, whilst in 1 patient bowel resection was

Table 2 ICU patients with AMI

\begin{tabular}{ll}
\hline ICU patients with AMI (1st January 2006-31 December 2015) \\
\hline Type of AMI & $N^{\circ}$ of cases \\
\hline EAMI & 6 \\
TAMI & 3 \\
VAMI & 1 \\
NOMI & 20 \\
\hline
\end{tabular}


Table 3 Laboratory and CT findings

\begin{tabular}{|c|c|c|c|c|c|c|c|c|}
\hline Patients & Age & $\begin{array}{l}\text { GOT (U/L) } \\
\text { nv: 0-31 }\end{array}$ & $\begin{array}{l}\text { GPT }(U / L) \\
\text { nv: } 0-31\end{array}$ & $\begin{array}{l}\mathrm{LDH}(\mathrm{U} / \mathrm{L}) \\
\mathrm{nv}: 240-480\end{array}$ & $\begin{array}{l}\text { CPK (U/L) } \\
\text { nv: 26-192 }\end{array}$ & $\begin{array}{l}\text { CREATININE mg/dl } \\
\text { nv: } 0,51-0,95\end{array}$ & $\begin{array}{l}\text { WBC vn 4-11 } \\
10 \wedge 3 \mathrm{uL}\end{array}$ & CT FINDINGS \\
\hline 1 & 66 & 520 & 489 & 3125 & 1223 & 5.1 & 26,28 & $\begin{array}{l}\text { negative for SMA obstruction, bowel } \\
\text { infarction, peritoneal collections }\end{array}$ \\
\hline 2 & 79 & 610 & 498 & 1225 & 251 & 1,3 & 22,3 & $\begin{array}{l}\text { negative for SMA obstruction, paralytic } \\
\text { ileum signs }\end{array}$ \\
\hline 3 & 75 & 426 & 286 & 1316 & 680 & 1,4 & 23,6 & $\begin{array}{l}\text { negative for SMA obstruction, paralytic } \\
\text { ileum signs }\end{array}$ \\
\hline 4 & 54 & 838 & 778 & 1198 & 889 & 1,3 & 24,68 & $\begin{array}{l}\text { negative for SMA obstruction, right colon } \\
\text { and ileum thickening }\end{array}$ \\
\hline 5 & 81 & 650 & 568 & 2218 & 1001 & 3,2 & 17,42 & $\begin{array}{l}\text { negative for SMA obstruction, diffuse colon } \\
\text { and bowel infarction, peritoneal collections }\end{array}$ \\
\hline 6 & 82 & 466 & 598 & 1589 & 996 & 1,9 & 15,69 & $\begin{array}{l}\text { negative for SMA obstruction, paralytic } \\
\text { ileum signs }\end{array}$ \\
\hline 7 & 61 & 835 & 687 & 1286 & 754 & 1,75 & 22,65 & $\begin{array}{l}\text { negative for SMA obstruction, right colon } \\
\text { and ileum thickening }\end{array}$ \\
\hline 8 & 90 & 589 & 410 & 1857 & 1028 & 2,6 & 14,8 & $\begin{array}{l}\text { negative for SMA obstruction, left colon } \\
\text { and ileum thickening }\end{array}$ \\
\hline 9 & 78 & 380 & 520 & 1635 & 987 & 2,4 & 15,1 & $\begin{array}{l}\text { negative for SMA obstruction, peritoneal } \\
\text { collections }\end{array}$ \\
\hline 10 & 76 & 489 & 475 & 856 & 385 & 1,9 & 23,2 & $\begin{array}{l}\text { negative for SMA obstruction, bowel } \\
\text { infarction }\end{array}$ \\
\hline 11 & 71 & 554 & 598 & 758 & 235 & 2,4 & 20,1 & $\begin{array}{l}\text { negative for SMA obstruction, bowel } \\
\text { infarction, peritoneal collections }\end{array}$ \\
\hline 12 & 61 & 665 & 689 & 1105 & 624 & 1,4 & 18,7 & $\begin{array}{l}\text { negative for SMA obstruction, paralytic } \\
\text { ileum signs }\end{array}$ \\
\hline 13 & 78 & 811 & 799 & 658 & 201 & 1,2 & 14,8 & $\begin{array}{l}\text { negative for SMA obstruction, bowel } \\
\text { infarction }\end{array}$ \\
\hline 14 & 69 & 715 & 684 & 2890 & 1425 & 3,3 & 18,4 & $\begin{array}{l}\text { negative for SMA obstruction, left colon } \\
\text { and ileum thickening }\end{array}$ \\
\hline 15 & 82 & 542 & 396 & 1687 & 1215 & 2,7 & 17,5 & $\begin{array}{l}\text { negative for SMA obstruction, paralytic } \\
\text { ileum signs }\end{array}$ \\
\hline 16 & 69 & 496 & 389 & 1420 & 893 & 2,6 & 18,84 & $\begin{array}{l}\text { negative for SMA obstruction, bowel } \\
\text { infarction, peritoneal collections }\end{array}$ \\
\hline 17 & 78 & 675 & 497 & 752 & 358 & 1,5 & 26,3 & $\begin{array}{l}\text { negative for SMA obstruction, paralytic } \\
\text { ileum signs }\end{array}$ \\
\hline 18 & 87 & 742 & 694 & 3869 & 1845 & 4,8 & 24.3 & $\begin{array}{l}\text { negative for SMA obstruction, left colon } \\
\text { and ileum thickening }\end{array}$ \\
\hline 19 & 78 & 868 & 688 & 1012 & 854 & 2,7 & 16,4 & $\begin{array}{l}\text { negative for SMA obstruction, paralytic } \\
\text { ileum signs }\end{array}$ \\
\hline 20 & 72 & 308 & 258 & 1536 & 1088 & 3,7 & 37,26 & $\begin{array}{l}\text { negative for SMA obstruction, peritoneal } \\
\text { collections }\end{array}$ \\
\hline
\end{tabular}

necessary to remove a necrotic segment. After a first look only 6 patients underwent bowel resection and its extension was since 15 up to $175 \mathrm{~cm}$. After resection in each patient a stoma and a mucous fistula were performed on the proximal and the distal stump respectively (Table 4).

Only one non-resected patient died $35 \mathrm{~h}$ after diagnosis of NOMI and before the second look for cardiac failure.

The second look, 48 h later, demonstrated 4 infarction recurrences in the group of resected patients and the onset of necrosis in 5 patients of non-resected group. A total of 15 resections were performed on 11 patients (Table 5).
Table 4 Extension of ischemic tract in NOMI patients

\begin{tabular}{lll}
\hline Extension of Ischemia In NOMl patients & \\
\hline Bowel site & $N^{0}$ of cases & 1st look resection cases \\
\hline Small Bowel and other splancnic & 14 & 0 \\
organs & 2 & 2 \\
lleum and right colon & 2 & 3 \\
Left colon & 3 & 1 \\
Entire colon & 1 & \\
\hline
\end{tabular}


Table 5 Recurrent necrosis after second look

\begin{tabular}{ll}
\hline Second look evaluation (48 h later) & $\mathrm{N}^{\circ}$ of recurrent necrosis \\
\hline Resected group & 4 \\
Non-resected group & 5 \\
\hline
\end{tabular}

Mortality rate was $6 / 20(30 \%)$ but it was much higher in resected group (5/11-45,5\%). Non-therapeutic laparotomy was avoided in $9 / 20$ patients $(45 \%)$ and in this group mortality rate was $1 / 9(11,1 \%)$. No morbidity was recorded related to laparoscopic procedure (Tables 6 and 7).

\section{Discussion}

NOMI is an infrequent type of AMI and accounts 20\% of cases. It is more frequent in critically ill patients and depends on combination of two distinct factors; low cardiac output and vasoconstrictive agents.

In literature, there are no high evidences about clinical findings, diagnosis and therapy of AMI and even less about NOMI. It is possible to found some case-series recording the experience of single centres and in this way, the present report is a contribution about diagnostic and therapeutic pathway in critically ill patients with suspicious NOMI.

It is well known that decreased mortality for AMI in last years is related to more aggressive therapeutic approach in occlusive shapes like surgical or nonsurgical blood flow restoration, resection of necrotic bowel, supportive intensive care. Moreover, the precocity of the treatment is highly related with its success.

But if in patients with occlusive forms the operative (surgical or not-surgical) approach ever follows diagnosis of AMI, in NOMI patients the treatment consists of pharmacological therapy with the need of continuous monitoring of ischemia. Only the onset of necrosis will require surgery. Because of the absence of tests that consent a determination of further bowel viability, laparoscopy can represent a diagnostic technique with high potential therapeutic options. We used it in NOMI patients both at the first and the second look to detect and remove dead bowel avoiding certain general and access-related risks associated with laparotomy [13].

Moreover, it is well known how the surgical stress could be life-threatening in these patients, and so to avoid a non-therapeutic laparotomy could be a very important step in their clinical course.

Table 6 Outcome of NOMl patients after treatment

\begin{tabular}{llll}
\hline $\begin{array}{l}\text { Outcome of NOMI patients } \\
\text { after treatment }\end{array}$ & $\mathrm{N}^{\circ}$ of cases & $\begin{array}{l}\text { Resected } \\
\text { group }\end{array}$ & $\begin{array}{l}\text { Non resected } \\
\text { group }\end{array}$ \\
\hline $\begin{array}{l}\text { Mortality } \\
\text { Morbidity related to }\end{array}$ & $0 / 20(30 \%)$ & $5 / 11(45,5 \%)$ & $1 / 9(11,1 \%)$ \\
\begin{tabular}{l} 
laparoscopy \\
\hline
\end{tabular} & 0 & 0 & 0 \\
\hline
\end{tabular}

Table 7 Mortality rate

\begin{tabular}{lll}
\hline Mortality & Cases/TOT & Percent \\
\hline First and second look negative & $1 / 9$ & 11,1 \\
1 st look positivity & $3 / 6$ & 50 \\
2 nd look positivity only & $2 / 5$ & 40 \\
\hline
\end{tabular}

In our centre, it was started 10 years ago, routinely use of laparoscopy in critical ill patients presenting clinical and radiological findings suggesting AMI. Laparoscopy was utilized like the last diagnostic procedure and the first therapeutic step.

Explorative laparoscopy allowed to avoid 9/20 (45\%) non-therapeutic laparotomies and at the same time it showed in 11 cases the presence of bowel necrosis; In 6 patients at the first look and in 9 patients at the second look. Four of second look resected patients had been already resected at the first look. The routinely execution of the second look $48 \mathrm{~h}$ after the first exploration of the abdomen is strongly suggested because of pathophysiology of NOMI [14]. The possible occurrence of low cardiac output due to surgical procedures (i.e. blood loss, ECC, etc.), in fact, can cause bowel ischemia but only in a variable percentage of cases necrosis will occur.

Then in our experience laparoscopy was positively used in patients with CT-scan diagnosed NOMI both for the first and the second look to detect the eventual onset of bowel necrosis. Its advantages were the possibility of bed-side performing without the surgical stress of laparotomic access.

\section{Conclusions}

NOMI represents a frequent type of AMI diagnosis. CT scan represent the golden standard in diagnosis of AMI but has a lower power in defining NOMI forms. Laparoscopy could be a feasible and safety surgical approach for diagnosis of ischaemic tract of bowel and to removing it. Our retrospective study demonstrate that laparoscopy don't increase morbidity and reduce mortality probably avoiding non-therapeutic laparotomy.

\section{Abbreviations}

AMI: Acute mesenteric ischemia; CT: Computed tomography; EAMI: Embolic acute mesenteric ischemia; ICU: Intensive care unit; NOMI: Non-occlusive mesenteric ischemia; SMA: superior mesenteric artery; TAMI: Thrombotic acute mesenteric ischemia; VAMI: Venous thrombosis acute mesenteric ischemia

\section{Acknowledgements}

Not applicable.

\section{Funding}

The authors declare that they have no funding. 


\section{Authors' contributions}

GC and AM contributed performing the operation and providing their casuistry from where this case series was extracted. NF, contributed as corresponding author to the elaboration of the data and production of the manuscript. TF, RT and LL contributed to the elaboration of data, production of tables and to the revision of language. GSa and GSc contributed to the work providing the discussion section. GG contribute as supervisor to the validation of data and to the conclusions. All authors read and approved the final manuscript.

\section{Competing interests}

The authors declare that they have no competing interests.

\section{Consent for publication}

Not applicable. Personal data are reported on an anonymous basis.

\section{Ethics approval and consent to participate}

Not applicable.

\section{Author details}

${ }^{1}$ General and Emergency Surgery-Policlinico P. Giaccone, University of Palermo, Via Liborio Giuffrè, 5, Palermo, Italy. ${ }^{2}$ General and Emergency. Surgery-Villa Sofia Hospita, Palermo, Italy.

\section{Received: 8 November 2016 Accepted: 13 January 2017}

Published online: 18 January 2017

\section{References}

1. Stoney RJ, Cunningham CG. Acute mesenteric ischemia. Surgery. 1993; 114(3):489-90.

2. Aouini F, Bouhaffa A, Baazaoui J, Khelifi S, Ben Maamer A, Houas N, Cherif A. Acute mesenteric ischemia: study of predictive factors of mortality. Tunis Med. 2012;90(7):533-6. French.

3. Haghighi PH, Lankarani KB, Taghavi SA, Marvasti VE. Acute mesenteric ischemia: causes and mortality rates over sixteen years in southern Iran. Indian J Gastroenterol. 2008;27(6):236-8.

4. Wadman M, Syk I, Elmstahl S. Survival after operations for ischemic bowel disease. Eur J Surg. 2000;166:872-7.

5. Tsai M-S, Lin C-L, Chen H-P, Lee P-H, Sung F-C, Kao C-H. Long-term risk of mesenteric ischemia in patients with inflammatory bowel disease: A 13-year nationwide cohort study in an Asian population. Am J Surg. 2015;210(1):80-6.

6. Yikilmaz A, Karahan OI, Senol S, Tuna IS, Akyildiz HY. Value of multislice computed tomography in the diagnosis of acute mesenteric ischemia. Eur J Radiol. 2011:80(2):297-302.

7. Furukawa A, Kanasaki S, Kono N, Wakamiya M, Tanaka T, Takahashi M, Murata K. CT diagnosis of acute mesenteric ischemia from various causes. Am J Roentgenol. 2009;192(2):408-16.

8. Acosta S, Bjorck M. Modern treatment of acute mesenteric ischaemia. Br J Surg. 2014;101:e100-8.

9. Sartelli M, Abu-Zidan FM, Catena F, Griffiths EA, Di Saverio S, Coimbra R Ordoñez CA, Leppaniemi A, Fraga GP, Coccolini F, Agresta F, Abbas A, Abdel Kader S, Agboola J, Amhed A, Ajibade A, Akkucuk S, Alharthi B, Anyfantakis D, Augustin G, Baiocchi G, Bala M, Baraket O, Bayrak S, Bellanova $G$, Beltràn $M A$, Bini $R$, Boal $M$, Borodach AV, Bouliaris $K$, Branger F, Brunelli D, Catani M, Che Jusoh A, Chichom-Mefire A, Cocorullo G, Colak E, Costa D, Costa S, Cui Y, Curca GL, Curry T, Das K, Delibegovic S, Demetrashvili Z, Di Carlo I, Drozdova N, El Zalabany T, Enani MA, Faro M, Gachabayov M, Giménez Maurel T, Gkiokas G, Gomes CA, Gonsaga RA, Guercioni G, Guner A, Gupta S, Gutierrez S, Hutan M, loannidis O, Isik A, Izawa Y, Jain SA, Jokubauskas M, Karamarkovic A, Kauhanen S, Kaushik R, Kenig J, Khokha V, Kim Jl, Kong V, Koshy R, Krasniqi A, Kshirsagar A, Kuliesius Z, Lasithiotakis K, Leão P, Lee JG, Leon M, Lizarazu Pérez A, Lohsiriwat V, López-Tomassetti Fernandez E, Lostoridis E, Mn R, Major P, Marinis A, Marrelli D, Martinez-Perez A, Marwah S, McFarlane M, Melo RB, Mesina C, Michalopoulos N, Moldovanu R, Mouaqit O, Munyika A, Negoi I, Nikolopoulos I, Nita GE, Olaoye I, Omari A, Ossa PR, Ozkan Z, Padmakumar R, Pata F, Pereira Junior GA, Pereira J, Pintar T, Pouggouras K, Prabhu V, Rausei S, Rems M, Rios-Cruz D, Sakakushev B, Sánchez de Molina ML, Seretis C, Shelat V, Simões RL, Sinibaldi G, Skrovina M, Smirnov D, Spyropoulos C, Tepp J, Tezcaner T, Tolonen M, Torba M, Ulrych J, Uzunoglu MY, van Dellen D, van Ramshorst GH, Vasquez $G$, Venara A, Vereczkei A,
Vettoretto N, Vlad N, Yadav SK, Yilmaz TU, Yuan KC, Zachariah SK, Zida M, Zilinskas J, Ansaloni L. Global validation of the WSES Sepsis Severity Score for patients with complicated intra-abdominal infections: a prospective multicentre study (WISS Study). World J Emerg Surg. 2015;10:61. doi:10.1186/ s13017-015-0055-0. eCollection 2015.

10. Tilsed JVT, et al. ESTES guidelines: Acute Mesenteric Ischaemia. Eur J Trauma Emerg Surg. 2016 Jan 28. Epub ahead of print.

11. Agrusa A, et al. Laparoscopic, SILS and three post cholecistectomy: a retrospective study. G Chir. 2013;34(9-10):249-53.

12. Cocorullo G, Tutino R, Falco N, Salamone G, Gulotta G. Three-port colectomy: reduced port laparoscopy for general surgeons. A single center experience. Ann Ital Chir. 2016;87:350-5

13. Nassau AH, et al. The abdominal drain. A convenient port for second look laparoscopy. Surg Endosc. 1996;10:1114-5.

14. Yanar $\mathrm{H}$, et al. Planned second look laparoscopy in te management of acute mesenteric ischemia. World J Gastroenterol. 2007;13(24):3350-3.

\section{Submit your next manuscript to BioMed Central and we will help you at every step:}

- We accept pre-submission inquiries

- Our selector tool helps you to find the most relevant journal

- We provide round the clock customer support

- Convenient online submission

- Thorough peer review

- Inclusion in PubMed and all major indexing services

- Maximum visibility for your research

Submit your manuscript at www.biomedcentral.com/submit
) Biomed Central 